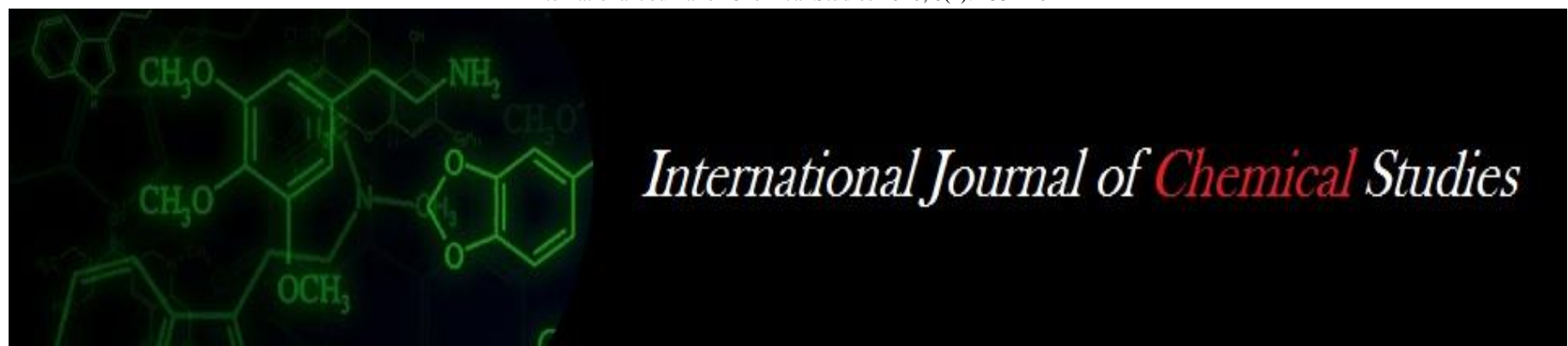

P-ISSN: 2349-8528

E-ISSN: 2321-4902

www.chemijournal.com

IJCS 2020; 8(2): 133-140

(C) 2020 IJCS

Received: 22-01-2020

Accepted: 24-02-2020

Yogranjan

Biotechnology Section,

JNKVV, College of Agriculture,

Tikamgarh, Madhya Pradesh,

India

Gyanesh K Satpute

Directorate of Soybean

Research-(ICAR), Indore,

Madhya Pradesh, India

Ajay Kumar Srivastava

Agro-meteorology Section,

JNKVV, College of Agriculture,

Tikamgarh, Madhya Pradesh,

India

Sudhakar P Mishra

Department of Crop Sciences,

MGCGVV, Chitrakoot, Satna,

Madhya Pradesh, India
Corresponding Author:

Yogranjan

Biotechnology Section,

JNKVV, College of Agriculture,

Tikamgarh, Madhya Pradesh,

India

\section{Characterization of genetic diversity for remodeling of elite accessions of sesame (Sesamum indicum $\mathbf{L}$.)}

\author{
Yogranjan, Gyanesh K Satpute, Ajay Kumar Srivastava and Sudhakar P \\ Mishra
}

DOI: https://doi.org/10.22271/chemi.2020.v8.i2b.8759

\begin{abstract}
Genetic diversity was studied in 61 white seeded type sesame (Sesamum indicum L.) accessions including 4 checks for 9 agro- morphological and 4 biochemical traits under field conditions by cluster and principal component analyses. Accessions were grown in the research field of JN Agricultural University, campus College of Agriculture, Tikamgarh, India in a plot size of $2.0 \times 1.50 \mathrm{~m}^{2}$ (3 rows with $45 \mathrm{~cm}$ row $\mathrm{x}$ row spacing). Cluster analysis divided the total 61 accessions into eight different nonoverlapping clusters during both the years of study i.e. 2015 and 2016. Data based on first and second years, PCs with Eigene value higher that 1.0 contributed $76.33 \%$ and $71.75 \%$ of the variability amongst accessions, respectively. Cluster pattern demonstrated sufficient diversity among the sesame accessions for various morphological and biochemical traits and some extent of association between different clusters. The results concluded that morpho-biochemical diversity in the studied material is governed by cumulative effect of a number of traits rather than the contribution of few specific traits and this diversity could well be utilized for future breeding strategies and germplasm conservation programs.
\end{abstract}

Keywords: Sesamum indicum L, genetic diversity, morphology, biochemical attributes

\section{Introduction}

Sesame (Sesamum indicum L.; $2 \mathrm{n}=26$.) is a popular oilseed crop cultivated for its quality edible oil, high protein, vitamin contents and balanced amino acid profile. It is possibly the most ancient known oilseed crop, whose domestication is lost in the mists of antiquity (Weiss, 2000). Even in the current era, sesame is valued as one of the highest oil content (up to 64\%) plant among major oilseed crops in the world (Wei et al. 2015; Dossaet al. 2017) [31, 10]. Sesame oil is enriched with high valued antioxidants such as sesaminol, sesamolin and tocopherol accounting for longer shelf life with minimal rancidity (Ashri 1998) ${ }^{[6]}$. Besides, sesame seed finds its application in various important culinary preparations. Studies on antioxidants, blood pressure lowering, anti-aging, the synergistic effect with tocopherols, serum lipid lowering etc. have been extensively reviewed (Namiki 2007) ${ }^{[19]}$. Despite such high value being placed on sesame seed, neither there have been good numbers of scientific studies validating these claims nor has the saleable gain been affixed to the crop. Moreover, the net outcome in terms of productivity is also not so notable with respect to other sesame growing countries in the world (Rai et al. 2016) ${ }^{[23]}$. The reasons for low productivity in the country might beassociated with lack of high yielding cultivated genotypes (Ram et al. 1990) ${ }^{[24]}$ and insufficient germplasm information with respect to exploitable genetic diversity (Were et al. 2006) ${ }^{[33]}$. There exists a wide and valuable morphological diversity for different desirable characters in sesame germplasms (Pathak et al. 2014; Pandey et al. 2015) [20, 21] however these diversity has not been fully exploited for sesame improvement of the existing cultivars (Wei et al. 2015) ${ }^{[31]}$. Now, in view of its well-known value, there seems an absolute but immediate requirement to develop highly heterotic hybrid and desirable transgressive segregants to achieve a gain in sesame productivity in the country.

Morphological variations in any crop species are the upshot of long term selection for varying objectives in different areas across the globe. Availability of large array of these genetic or morphological variations caters crop improvement programme for better economic characters as 'quantifying genetic diversity' and 'studying the accessiblepatterns of the variability' are the 
leading steps in plant breeding and germplasm conservation (Mohammadi and Prasanna, 2003) ${ }^{[18]}$. Estimates of genetic diversity and relationships among germplasm accessions are vital for facilitating efficient germplasm selection and management (Siddique et al. 2012) ${ }^{[25]}$. Many advanced tools such as isozymes, and molecular markers are now available at ease for studying variability and relationships among accessions (Trick et al. 2009; Cheng et al. 2009; Allender and King 2010) ${ }^{[29,8,4]}$. However, morphological characterization is still the primary step in the description and classification of germplasm (Smykal et al. 2008) ${ }^{[26]}$. A number of quantitative taxonomic techniques used to be in practice to classify and measure the patterns of phenotypic diversity in the relationships of species and germplasm collections of variety of crops (Gomez-Campo 1999) ${ }^{[14]}$. Among these, principal component analysis (PCA) and cluster analysis have analogous efficacy to establish the most suitable cross combinations. The present study attempted to characterize and classify the phenotypic variation and affinities among the different sesame germplasm accessions using these statistical techniques.

\section{Materials and Methods}

Sixty one accessions of white seeded sesame accessions including 4 checks were evaluated for 9 agro- morphological and 4 biochemical traits during the years 2015 and 2016 in the research field of JN Agricultural University, campus College of Agriculture, Tikamgarh, India in a plot size of $2.0 \times 1.50$ $\mathrm{m}^{2}$ (i.e. in 3 rows with $45 \mathrm{~cm}$ row $\mathrm{x}$ row spacing) (Table 1 and 2). For seed bed preparation pre-sowing irrigation was applied and sowing was carried out under optimum moisture conditions. Recommended doses of all essential fertilizers were applied at the time of land preparation. Planting of the experiments was done by hand drills and thinning was carried out two weeks after germination to maintain optimum plant population. Weeds were controlled manually. The data were recorded on five randomly sampled plants from each accession for days to $50 \%$ flowering, days to maturity, plant height $(\mathrm{cm})$, number of branches plant ${ }^{-1}$, capsule length, number of capsules plant ${ }^{-1}$, number of seeds capsule ${ }^{-1}, 1000$ seed weight $(\mathrm{g})$ and seed yield plant $^{-1}(\mathrm{~g})$. Biochemical analysis of seed for oil content $(\%)$, and fatty acid profile (oleic acid, palmitic acid and linoleic acid content (\%) was carried out at Biochemistry laboratory, AICRP (Sesame), JNKVV campus Jabalpur (Table 3).

\section{Statistical Analysis}

Basic statistical analysis of different morphological and biochemical characters was carried out (Gomez and Gomez 1984) ${ }^{[13]}$. Cluster and principal component analyses were carried out on nine morphological and four biochemical traits for the years 2015 and 2016 (Sneath and Sokal 1973) [27]. Basic statistics of all accessions is shown in Table 4.

\section{Results and Discussion}

A successful breeding program mainly relies on the magnitude of agro-morphological variability. Investigating the extent of diversity is vital for its conservation and utilization in crop improvement programme (Mohamed et al. 2012) ${ }^{[17]}$. The agro-morphological traits used in the study confirmed a noticeable variation among accessions. The coefficients defining five principal components of the data for S. indicum in 2015 are given in (Table 5; Fig.1).

The first principal component contributed $18.85 \%$ of total variance and is primarily contributed by days to $50 \%$ flowering (0.04), days to maturity $(0.30)$, plant height $(0.18)$, branches plant ${ }^{-1}(0.13)$, capsules plant ${ }^{-1}(0.50)$, seeds capsule ${ }^{-1}$ (0.22) and 1000-seed weight (0.02). The second principal component accounted for $16.30 \%$, having $50 \%$ flowering $(0.37)$, days to maturity $(0.33)$, capsules plant ${ }^{-1}(0.27), 1000-$ seed weight (0.83), oleic acid (0.06), palmitic acid (0.047), linoleic acid (0.166). The third component contributed $13.80 \%$ of the total variation and positively determined by $50 \%$ flowering (0.10), plant height $(0.12)$, capsule length $(0.14)$, capsules plant ${ }^{-1}(0.14), 1000$-seed weight $(0.22)$, seed yield plant ${ }^{-1}(0.25)$, and palmitic acid (0.212). The forth principal component shared for $10.07 \%$ of the total variation and contributed by days to $50 \%$ flowering $(0.28)$, plant height $(0.19)$, capsules plant $^{-1}(0.23)$, seeds capsule ${ }^{-1}(0.16)$, seed yield plant ${ }^{-1}(0.16)$, oil content $(0.06)$,palmitic acid(0.24), and linoleic acid(0.06). The total contribution of the fifth component were $9.10 \%$ having $50 \%$ flowering (0. 97), days to maturity (0.16), plant height $(0.23)$, capsules plant ${ }^{-1}(0.19)$, seeds capsule ${ }^{-1}(0.25), 1000$-seed weight $(0.24)$, seed yield plant $^{-1}(0.17)$ and oleic acid (0.03). The sixth component attributed for $8.23 \%$ and determined by days to $50 \%$ flowering (0.31), plant height $(0.13)$, capsule length $(0.14)$, 1000 -seed weight $(0.28)$, seed yield plant ${ }^{-1}(0.02)$, oil content (0. 66), linoleic acid (0. 26). All these studies disclosed complex relationships among the accessions and traits, and concluded that the differentiation of the genotypes into different cluster was because of a combined outcome of multiple characters instead of contribution of specific few characters.

The coefficients defining six principal components of the data for $S$. indicum in 2016 is indicated in Table 6 (fig. 2). The first principal component contributes $29.31 \%$ of total variance in morphological and biochemical characters and is primarily contributed by $50 \%$ flowering $(0.18)$, days to maturity $(0.20)$, capsules plant ${ }^{-1}(0.47), 1000$-seed weight $(0.04)$, oleic acid (0.08), palmitic acid (0.06) and linoleic acid (0.20). The second component accounted for $14.76 \%$ and positively associated with days to maturity $(0.35), 50 \%$ flowering (0.05),plant height $(0.12)$, capsules plant ${ }^{-1}(0.05), 1000$-seed weight (0.23), palmitic acid (0.17), oleic acid (0.06), linoleic acid (0.17). The third component contributed $10.03 \%$ and determined by days to $50 \%$ flowering $(0.45)$, days to maturity $(0.28)$, branches plant ${ }^{-1}(0.07)$, capsule length $(0.26)$, capsules plant $^{-1}(0.07)$, seeds capsule ${ }^{-1}(0.11)$ and 1000 -seed weight (0.42). The forth component accounted for $9.09 \%$ having days to $50 \%$ flowering $(0.20)$, capsule length $(0.09)$, seeds capsule ${ }^{-}$ ${ }^{1}(0.37)$, palmitic acid (0.16). The fifth component contributed $8.57 \%$ and associated with days to $50 \%$ flowering (0.23), plant height (0.06), capsules plant ${ }^{-1}(0.09), 1000$-seed weight $(0.21)$, oil content $(0.62)$ and linoleic acid $(0.25)$.

It was observed that, in 2015, among the seven principal components, six showed Eigene value higher than 1.0 and accounted for $76.33 \%$ of the total variation among 61 genotypes of sesame while in 2016, among the six principal components, five showed Eigene value higher than 1.0 and accounted for $71.755 \%$ of the total variation. In 2015, principal component analysis showed association in PCI with number of capsules per plant, days to maturity, number of seeds per capsule, PCII with days to $50 \%$ flowering, number of capsules per plant and days to maturity and PCIII with seed yield per plant and 1000-seed weight, whereas in 2016, PCA showed association in PCI with number of capsules per plant, linoleic acid, days to maturity, PCII with days to maturity, 1000 seed weightand PCIII with days to 50\% flowering, 1000 -seed weight. The comparable results were also reported by Menzir (2012) ${ }^{[16]}$, Tripathi et al. (2013) ${ }^{[30]}$, and Hika et al. 
(2015) ${ }^{[15]}$ in sesame while by Ali et al. (2011) ${ }^{[1]}$ in sorghum, Ahlawat et al. (2008) ${ }^{[1]}$ and Golabadi et al. (2006) ${ }^{[12]}$ in wheat. Here, during both the years, PCI to PCIII accounted for almost $50 \%$ of the total variations, therefore traits with high coefficients in the PCI to PCIII should be considered as more significant because these axes explain almost half of the whole variation.

The dendrogram constructed on the basis of $S$. indicum divided the total accessions into eight major groups in the year 2015 (Fig. 3). The 61 genotypes were grouped into eight different non-overlapping clusters. The distribution of 61 sesame accessions into eight clusters is given in Table 7. Maximum number of genotypes grouped in cluster III (12 genotypes) and minimum in cluster VII (2 genotypes). The table revealed that cluster I consisted of 4 genotypes and had the lowest cluster mean values of 1000 seed weight (3.09), whereas it showed no maximum cluster mean values for any trait. Cluster II had 9 genotypes which did not show any maximum and minimum cluster mean values. The cluster mean values under this cluster for days to $50 \%$ flowering were (41.24), days to maturity (104.19), plant height (77.65), branching habit (1.96), number of capsules per plant (49.44), number of seeds per capsule (74.66) and seed yield per plant (5.81). Cluster III consisted of 12 genotypes and had the minimum cluster mean values of number of seeds per capsule (57.21), whereas it showed no maximum cluster mean values for any trait. Cluster IV had 11 genotypes which exhibited highest cluster mean values for plant height (92.86), whereas it had minimum cluster mean values for days to $50 \%$ flowering (39.82), days to maturity (100.57), capsule length (2.21), and palmitic acid (7.81). Cluster V had 11 genotypes which exhibited highest cluster mean values for number of branches per plant (3.00) and number of seeds per capsule (80.68) whereas it had minimum cluster mean values for 1000 seed weight (2.30). The cluster mean values, for oil content and linoleic acid were 42.02 and 51.40 respectively. Cluster VI had 5 genotypes which exhibited highest cluster mean values for number of days to maturity (106.68) whereas it had minimum cluster mean values for number of capsules per plant (34.75), seed yield per plant (3.15), and oleic acid (23.91). The cluster mean value for palmitic acid was 10.14. Cluster VII had 2 genotypes which exhibited highest cluster mean values for days to $50 \%$ flowering (43.20), capsule length (2.40) and palmitic acid (10.27) whereas it had minimum cluster mean values for number of number of branches per plant (0.33), overall oil content (41.02) and linoleic acid (38.28). Cluster VIII had 7 genotypes which exhibited highest cluster mean values for number of capsules per plant (50.75), seed yield per plant (6.71), oil content (54.68), oleic acid (39.08) and linoleic acid (53.08) whereas it had minimum cluster mean values for plant height (48.97).

The dendrogram constructed on the basis of S. indicum during the year 2016 revealedeight major groups (Fig. 4). The 61 genotypes were grouped into eight different non-overlapping clusters. The distribution of 61 sesame accessions into eight clusters is given in Table 8 . The table revealed that cluster I consisted of 7 genotypes and had the lowest cluster mean values of plant height (72.75), whereas it showed no maximum cluster mean values for any trait. Cluster II had 11 genotypes which showed maximum cluster mean values for 1000 seed weight (3.05) while it did not show minimum cluster mean values for any trait. Cluster III consisted of 4 genotypes which exhibited highest cluster mean values for capsule length (2.56), whereas it had minimum cluster mean values for days to maturity (100.30), seed yield per plant (4.42), oleic acid (22.78) and linoleic acid (36.64). Cluster IV had 11 genotypes which neither exhibited highest cluster mean values nor the minimum cluster mean values for any trait. Cluster V had 12 genotypes which exhibited highest cluster mean values for days to maturity (108.38) and seed yield per plant (6.78) whereas it had minimum cluster mean values for number of branches per plant $(0.07)$, number of capsules per plant (2.02) and overall oil content (40.28). The cluster mean value for palmitic acid was 49.71. Cluster VI had 8 genotypes which exhibited highest cluster mean values for palmitic acid (8.61) whereas it had minimum cluster mean values for number of capsule length (2.03) and number of seeds per capsule (53.63). The cluster mean value for days to $50 \%$ flowering was 42.25 . Cluster VII had 6 genotypes which exhibited highest cluster mean values for plant height (89.44), number of branches per plant (2.59), number of capsules per plant (37.13) and number of seeds per capsule (73.66) whereas it had minimum cluster mean values for days to $50 \%$ flowering (38.95), 1000 seed weight (2.43) and palmitic acid (7.49).Cluster VIII had 2 genotypes which exhibited highest cluster mean values for days to $50 \%$ flowering (43.85), overall oil content (54.95), Oleic Acid (39.08) and linoleic acid (53.08). The results of cluster analysis for the years 2012 and 2013 suggested that there is enough variation among the germplasm accessions for different agro-morphological and biochemical traits. Accessions with greater similarity for agro-morphological and seed quality traits were placed in the same cluster; however, the accessions from the nearby/same sites were not necessarily placed in the same cluster. The findings of present studies are in agreement with those of Furat and Uzun (2010) ${ }^{[11]}$ who studied 103 sesame germplasm accessions those were divided into 8 main clusters. They were of the view that Clustering of landraces was not associated with the geographical distribution instead accessions were mainly grouped due to their morphological differences. Similarly, Arriel et al. (2007) [5] conducted divergence studies with 108 accessions of sesame germplasm which formed seven conglomerates. They reported that many derivatives of the cross fell into the same cluster but in many cases, in spite of common ancestry, many descendents spread over different clusters. The findings of present studies also coincided with the work of Bedigian et al., $1986^{[7]}$, Dixit and Swain (2000) ${ }^{[9]}$, Solanki and Gupta, (2003) ${ }^{[28]}$ and Akbar et al. (2011) ${ }^{[2]}$. This may be on account of migration of the sesame materials from one region to another in collection sites. Although a lot of literatures described sesame as an autogamous plant, however, recent findings raise the possibility of sesame being natural out-crossing (Pathirana 1994). Some ecological conditions could also lead to gene flow between populations from different geographical origins. Conclusively, the study indicated existence of high degree of genetic diversity in the germplasm collections. The eight clusters in divergence analysis contained germplasm of heterogeneous origin thereby indicating no parallelism between genetic and geographic diversity. Therefore, crosses between the members of clusters separated by high inter cluster distance are likely to produce desirable segregants. Moreover, the different clusters showed considerable differences in intra-cluster group means for all the thirteen characters. Therefore, crosses between members of cluster having high cluster mean for important characters coupled with high inter-cluster distances between them are likely to be more rewarding. 
Table 1: Sesamum indicum L. germplasm accessions used in the study

\begin{tabular}{|c|c|c|c|c|c|}
\hline S.\# & Accessions & Name under study & S.\# & Accessions & Name under study \\
\hline 1 & KMR-60 & TKGSE-11-1 & 30 & $(\mathrm{VKS}-272$ x SI-250)-2-2-1 & TKGSE-11-30 \\
\hline 2 & KMR-31 & TKGSE-11-2 & 31 & (TC-25 x KMR-115)-6 & TKGSE-11-31 \\
\hline 3 & SI-233 & TKGSE-11-3 & 32 & VKS-272 x SI-1446)-5-1-1 & TKGSE-11-32 \\
\hline 4 & KMR-51 & TKGSE-11-4 & 33 & (GT-1 x TKG-22)-1-2-2 & TKGSE-11-33 \\
\hline 5 & SI-3263-1 & TKGSE-11-5 & 34 & (TKG-307 x N-32)-1 & TKGSE-11-34 \\
\hline 6 & KMR-61 & TKGSE-11-6 & 35 & (GT-1 x TKG-22)-1-4-2 & TKGSE-11-35 \\
\hline 7 & KMR-394 & TKGSE-11-7 & 36 & (GT-1 x TKG-22)-4-1-2 & TKGSE-11-36 \\
\hline 8 & SI-107-B & TKGSE-11-8 & 37 & (JTS-8 x SI-225-3)-2-1-2 & TKGSE-11-37 \\
\hline 9 & IS-405 & TKGSE-11-9 & 38 & $($ RT-46 x N-32)-1-2 & TKGSE-11-38 \\
\hline 10 & IS-8 & TKGSE-11-10 & 39 & $(\mathrm{SI}-911 \times \mathrm{N}-32) 1-1$ & TKGSE-11-39 \\
\hline 11 & NIC-10622 & TKGSE-11-11 & 40 & $($ SI-1556 x SI-250)-6-2 & TKGSE-11-40 \\
\hline 12 & IS-35-1-A & TKGSE-11-12 & 41 & (SI-928 x N-32)-3-1-1 & TKGSE-11-41 \\
\hline 13 & EC-303311-1 & TKGSE-11-13 & 42 & (SI-928 x N-32)-3-1-2 & TKGSE-11-42 \\
\hline 14 & SI-2039-A & TKGSE-11-14 & 43 & $($ SI-1556 x TKG-308)-1 & TKGSE-11-43 \\
\hline 15 & SI-8459 & TKGSE-11-15 & 44 & (RT-46 x TKG-306)-1-1 & TKGSE-11-44 \\
\hline 16 & SI-1782A & TKGSE-11-16 & 45 & $(\mathrm{RT}-46 \times \mathrm{TKG}-306)-2-2$ & TKGSE-11-45 \\
\hline 17 & EC-52000145 & TKGSE-11-17 & 46 & (AT-66 $\times$ TC-25)-1-2 & TKGSE-11-46 \\
\hline 18 & S-01159-B & TKGSE-11-18 & 47 & (AT-66 x TC-25)-2-1 & TKGSE-11-47 \\
\hline 19 & KMR-39 & TKGSE-11-19 & 48 & (JLT-7 x CST-785)-1-2-1 & TKGSE-11-48 \\
\hline 20 & KIS-300-A & TKGSE-11-20 & 49 & (JLT-7 x CST-785)-1-2-2 & TKGSE-11-49 \\
\hline 21 & IS-390 & TKGSE-11-21 & 50 & (JLT-7 x CST-785)-2-1 & TKGSE-11-50 \\
\hline 22 & SI-3257 & TKGSE-11-22 & 51 & (JLT-7 x CST-785)-2-4 & TKGSE-11-51 \\
\hline 23 & KMR-89 & TKGSE-11-23 & 52 & $(\mathrm{JTS}-111 \times \mathrm{TC}-5252)$ & TKGSE-11-52 \\
\hline 24 & NIC-17912-B & TKGSE-11-24 & 53 & $(\mathrm{JTS}-111 \times \mathrm{TC}-5252)$ & TKGSE-11-53 \\
\hline 25 & NIC-8588 & TKGSE-11-25 & 54 & (JTS-111 x N-32)-2 & TKGSE-11-54 \\
\hline 26 & NIC-8584 & TKGSE-11-26 & 55 & $(\mathrm{~K}-5142 \times \mathrm{HT}-36)$ & TKGSE-11-55 \\
\hline 27 & NIC-10630 & TKGSE-11-27 & 56 & $(\mathrm{VK}-5262 \times \mathrm{CST}-785)$ & TKGSE-11-56 \\
\hline 28 & KMS-4-258 & TKGSE-11-28 & 57 & $(\mathrm{VK}-5262 \times \mathrm{CST}-785)$ & TKGSE-11-57 \\
\hline 29 & (JTS-8 x SI-225-3)-2-2-1 & TKGSE-11-29 & & & \\
\hline
\end{tabular}

Table 2: Characters of the check entries suitable for export quality traits

\begin{tabular}{|c|c|}
\hline Check entries & Promising characters \\
\hline TKG-55 & $\begin{array}{c}\text { Resistant to Phytophthora blight and Macrophomina stem/root rot and free from bacterial diseases and leaf curl } \\
\text { diseases,moderately resistant to leaf roller and capsule borer. Oil content }-52.56 \%, \text { Being early in maturity it escapes } \\
\text { drought, yield-610 kg/ha. }\end{array}$ \\
\hline GT-2 & White bold seeded, high Oil content, export quality, resistant to cyst-nematodes. \\
\hline JTS-08 & Bold white seeded,Maturity period-90-100 days, Oil content $-53 \%$, yield-610 kg/ha \\
\hline Phule Til-1 & White bold seeded, lustrous, export quality, drought tolerant, yield-600 $\mathrm{kg} / \mathrm{ha}$. \\
\hline
\end{tabular}

Table 3: Morphological and biochemical traits recorded in the 61 accessions of Sesamum indicum L.

\begin{tabular}{|c|c|c|}
\hline Trait designation & Code & Description of the trait \\
\hline Days to $50 \%$ flowering & $50 \%$ DFI & Number of days to $50 \%$ plants having $1^{\text {st }}$ flower open from date of planting \\
\hline Days to maturity & DOM & Number of days to reach physiological maturity from date of planting \\
\hline Plant height & $\mathrm{PH}$ & $\begin{array}{l}\text { At maturity, plant height was recorded in } \mathrm{cm} \text { from ground level to the extremity of plant, } \\
\text { determined as mean of } 5 \text { random plants }\end{array}$ \\
\hline Capsule Length & CL & Recorded in $\mathrm{cm}$ from base to the tip of 10 capsules of each accession and average was taken \\
\hline Number of capsules plant ${ }^{-1}$ & NCPP & Counted from the same 5 plants used for counting number of branches per plant \\
\hline Number of seeds capsule ${ }^{-1}$ & NSPC & Obtained from the same 10 capsules used for measuring capsule length \\
\hline Number of branches plant ${ }^{-1}$ & NBPP & $\begin{array}{l}\begin{array}{l}\text { Number of branches originated from the main stem which gave rise to other capsule bearing } \\
\text { branches }\end{array} \\
\end{array}$ \\
\hline 1000- seed weight (gm) & SW & An average of 10 samples per accession using seed counter \\
\hline Seed yield plant ${ }^{-1}(\mathrm{~g})$ & SY & $\begin{array}{l}\text { Recorded by harvesting ten individual plants and then averaged to calculate seed yield per } \\
\text { plant in each accession }\end{array}$ \\
\hline Oil Content (\%) & $\mathrm{OC}$ & \multirow{4}{*}{$\begin{array}{l}\text { Determined from well cleaned and dried seed samples of 8-10 gm by Gas Liquid } \\
\text { Chromatography }\end{array}$} \\
\hline Oleic Acid Content (\%) & $\mathrm{OA}$ & \\
\hline Palmitic Acid Content (\%) & PA & \\
\hline Linoleic Acid Content (\%) & LA & \\
\hline
\end{tabular}


Table 4: Basic statistics of agro-morphological and biochemical traits of 61 accessions of Sesamum indicum

\begin{tabular}{|c|c|c|c|c|c|c|c|}
\hline \multirow{2}{*}{ Traits } & \multicolumn{2}{|c|}{ Range } & \multirow{2}{*}{\multicolumn{2}{|c|}{ Mean \pm SE }} & \multirow[t]{2}{*}{ Variance } & \multirow[t]{2}{*}{ GCV (\%) } & \multirow[t]{2}{*}{ PCV (\%) } \\
\hline & Minimum & Maximum & & & & & \\
\hline Days to $50 \%$ Flowering & 35.60 & 47.27 & 41.20 & \pm 0.35 & $4.91^{*}$ & 1.26 & 6.71 \\
\hline Days to Maturity & 97.52 & 108.35 & 103.27 & \pm 0.28 & $3.92^{*}$ & 0.47 & 2.12 \\
\hline Plant Height $(\mathrm{cm})$ & 48.97 & 107.63 & 75.49 & \pm 1.50 & $120.63^{*}$ & 5.59 & 15.55 \\
\hline Branching habit & 0.000 & 5.00 & 1.81 & $\underline{ \pm 0.13}$ & $0.88^{*}$ & 20.88 & 57.16 \\
\hline Capsule Length & 1.74 & 2.85 & 2.32 & \pm 0.02 & 0.03 & 7.34 & 7.93 \\
\hline Capsule/ Plant & 31.42 & 55.42 & 45.51 & \pm 0.78 & $36.12^{* *}$ & 5.61 & 13.42 \\
\hline Seeds/ Capsule & 43.43 & 90.35 & 67.98 & \pm 1.21 & 91.54 & 10.28 & 13.92 \\
\hline 1000 Seed Weight (gm) & 2.20 & 4.24 & 2.79 & +0.06 & $0.22^{*}$ & 3.88 & 16.63 \\
\hline Seed Yield/ Plant (gm) & 2.05 & 7.75 & 5.34 & \pm 0.18 & $1.96^{*}$ & 13.10 & 26.15 \\
\hline Oil Content $(\%)$ & 37.52 & 54.68 & 42.97 & \pm 0.37 & $7.99^{*}$ & 3.78 & 6.73 \\
\hline Oleic Acid (\%) & 21.44 & 39.08 & 28.46 & +0.49 & $11.49^{*}$ & 7.92 & 13.35 \\
\hline Palmitic Acid (\%) & 6.19 & 11.00 & 8.141 & \pm 0.16 & $1.36^{*}$ & 6.65 & 14.99 \\
\hline Linoleic Acid (\%) & 35.98 & 53.20 & 44.004 & \pm 0.66 & $22.57^{* *}$ & 8.07 & 11.66 \\
\hline
\end{tabular}

$*$ and $* *$ are statistically significant at 0.05 and 0.01 level, respectively

Table 5: Principal components for agro-morphological and biochemical traits in 61 germplasm accessions of sesame during 2015

\begin{tabular}{|c|c|c|c|c|c|c|}
\hline & 1 Vector & 2 Vector & 3 Vector & 4 Vector & 5 Vector & 6 Vector \\
\hline Eigene Value (Root) & 2.450 & 2.118 & 1.794 & 1.309 & 1.182 & 1.070 \\
\hline Proportion of variance (\%) & 18.846 & 16.290 & 13.801 & 10.068 & 9.094 & 8.234 \\
\hline Cumulative Variance (\%) & 18.846 & 35.135 & 48.937 & 59.005 & 68.099 & 76.333 \\
\hline \multicolumn{7}{|c|}{ Traits } \\
\hline Days to 50\% Flowering & 0.035 & 0.371 & 0.101 & 0.281 & 0.497 & 0.306 \\
\hline Days to Maturity & 0.303 & 0.331 & 0.144 & -0.143 & 0.159 & -0.465 \\
\hline Plant Height (cm) & 0.184 & -0.491 & 0.124 & 0.193 & 0.225 & 0.128 \\
\hline Branching habit & 0.132 & -0.441 & -0.285 & -0.344 & -0.041 & -0.160 \\
\hline Capsule Length & -0.389 & -0.224 & 0.143 & -0.343 & -0.143 & 0.141 \\
\hline Capsule/ Plant & 0.493 & 0.265 & 0.136 & 0.229 & 0.187 & -0.116 \\
\hline Seeds/ Capsule & 0.217 & -0.284 & -0.352 & 0.162 & 0.246 & -0.161 \\
\hline 1000 Seed Weight (gm) & 0.024 & 0.083 & 0.222 & -0.676 & 0.236 & 0.284 \\
\hline Seed Yield/ Plant (gm) & -0.488 & -0.255 & 0.245 & 0.161 & 0.173 & 0.021 \\
\hline Oil Content (\%) & -0.133 & -0.103 & -0.376 & 0.063 & -0.116 & 0.656 \\
\hline Oleic Acid (\%) & -0.336 & 0.060 & -0.530 & -0.017 & 0.028 & -0.100 \\
\hline Palmitic Acid (\%) & -0.061 & 0.047 & 0.212 & 0.240 & -0.672 & 0.000 \\
\hline Linoleic Acid (\%) & -0.205 & 0.166 & -0.364 & 0.058 & -0.092 & 0.259 \\
\hline
\end{tabular}

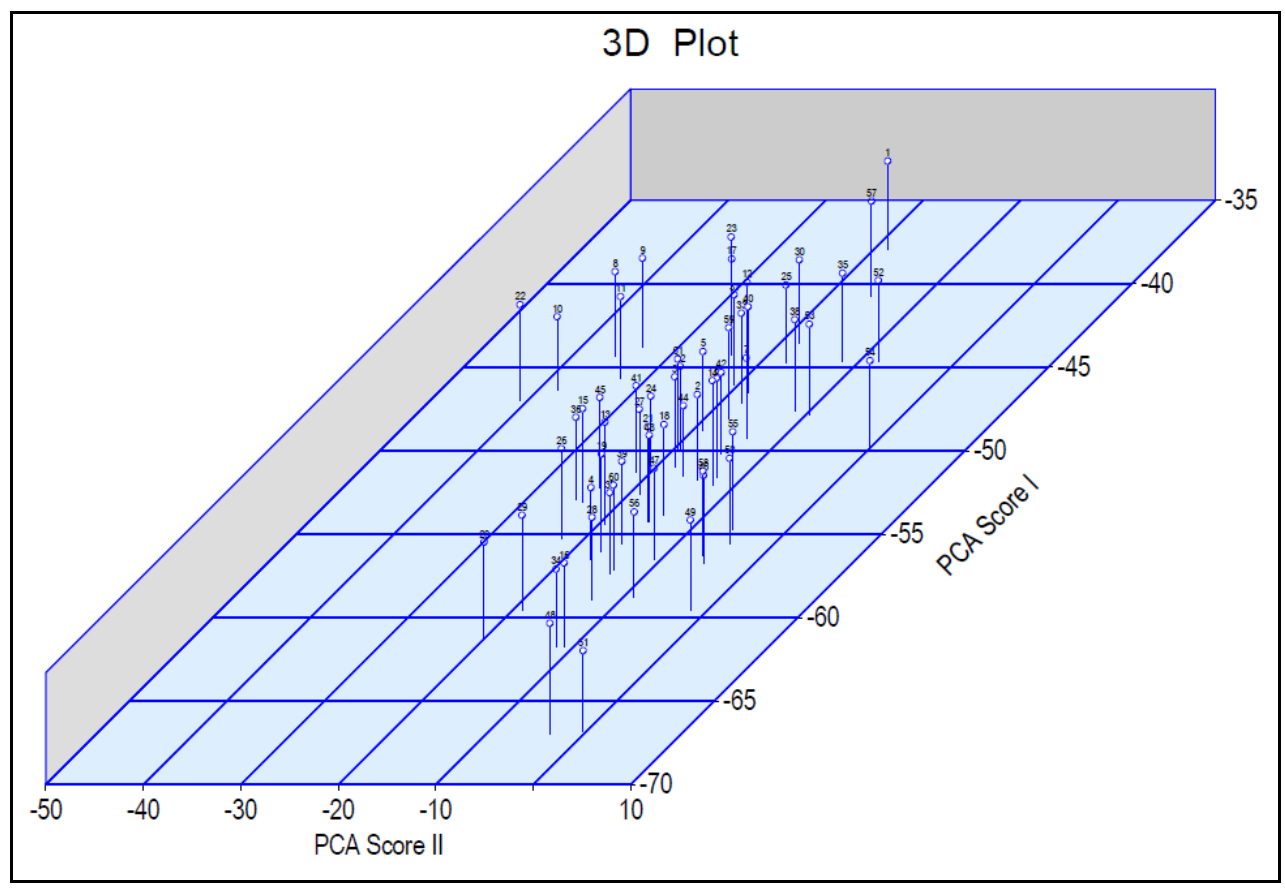

Fig 1: Three dimensional diagram of principal components analysis: Sesame 2015 
Table 6: Principal components for agro-morphological and biochemical traits in germplasm accessions of sesame 2015

\begin{tabular}{|c|c|c|c|c|c|}
\hline & 1 Vector & 2 Vector & 3 Vector & 4 Vector & 5 Vector \\
\hline Eigene Value (Root) & 3.810 & 1.918 & 1.304 & 1.182 & 1.114 \\
\hline Proportion of variance (\%) & 29.306 & 14.755 & 10.034 & 9.095 & 8.566 \\
\hline Cumulative Variance (\%) & 29.306 & 44.061 & 54.094 & 63.189 & 71.755 \\
\hline \multicolumn{7}{|c|}{ Traits } \\
\hline Days to 50\% Flowering & 0.181 & 0.045 & 0.445 & 0.198 & 0.232 \\
\hline Days to Maturity & 0.197 & 0.347 & 0.277 & -0.068 & -0.510 \\
\hline Plant Height (cm) & -0.444 & 0.108 & -0.095 & -0.179 & 0.057 \\
\hline Branching habit & -0.421 & -0.095 & 0.074 & -0.109 & -0.032 \\
\hline Capsule Length & -0.353 & -0.296 & 0.260 & 0.086 & -0.145 \\
\hline Capsules/ Plant & 0.472 & 0.048 & 0.072 & -0.105 & 0.091 \\
\hline Seeds/ Capsule & -0.391 & -0.205 & 0.108 & 0.368 & -0.065 \\
\hline 1000 Seed Wt (gm) & 0.040 & 0.226 & 0.420 & -0.539 & 0.214 \\
\hline Seed Yeild/ Plant (gm) & -0.017 & -0.104 & -0.204 & -0.652 & -0.280 \\
\hline Oil Content (\%) & -0.012 & -0.360 & -0.266 & -0.059 & 0.617 \\
\hline Oleic Acid (\%) & 0.076 & -0.612 & -0.032 & -0.097 & -0.043 \\
\hline Palmitic Acid (\%) & 0.061 & 0.171 & -0.556 & 0.155 & -0.279 \\
\hline Linoleic Acid (\%) & 0.204 & -0.361 & -0.165 & -0.078 & 0.253 \\
\hline
\end{tabular}

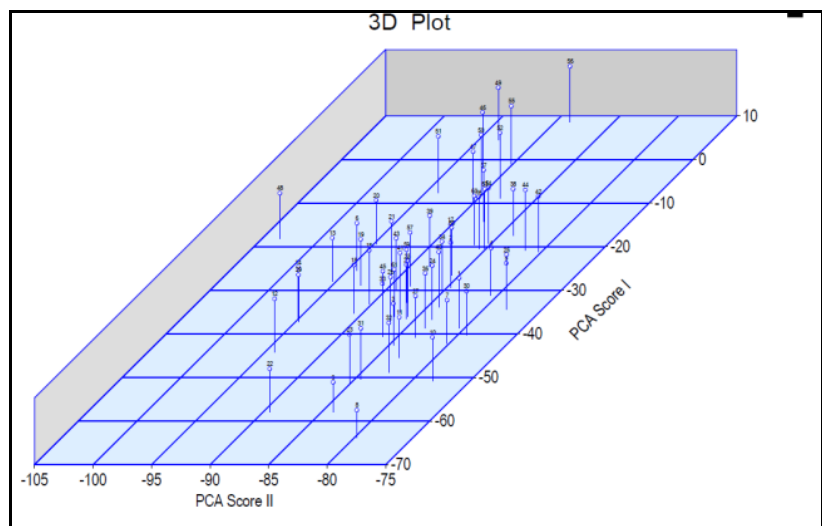

Fig 2: Three dimensional diagram of principal components analysis: Sesame 2016

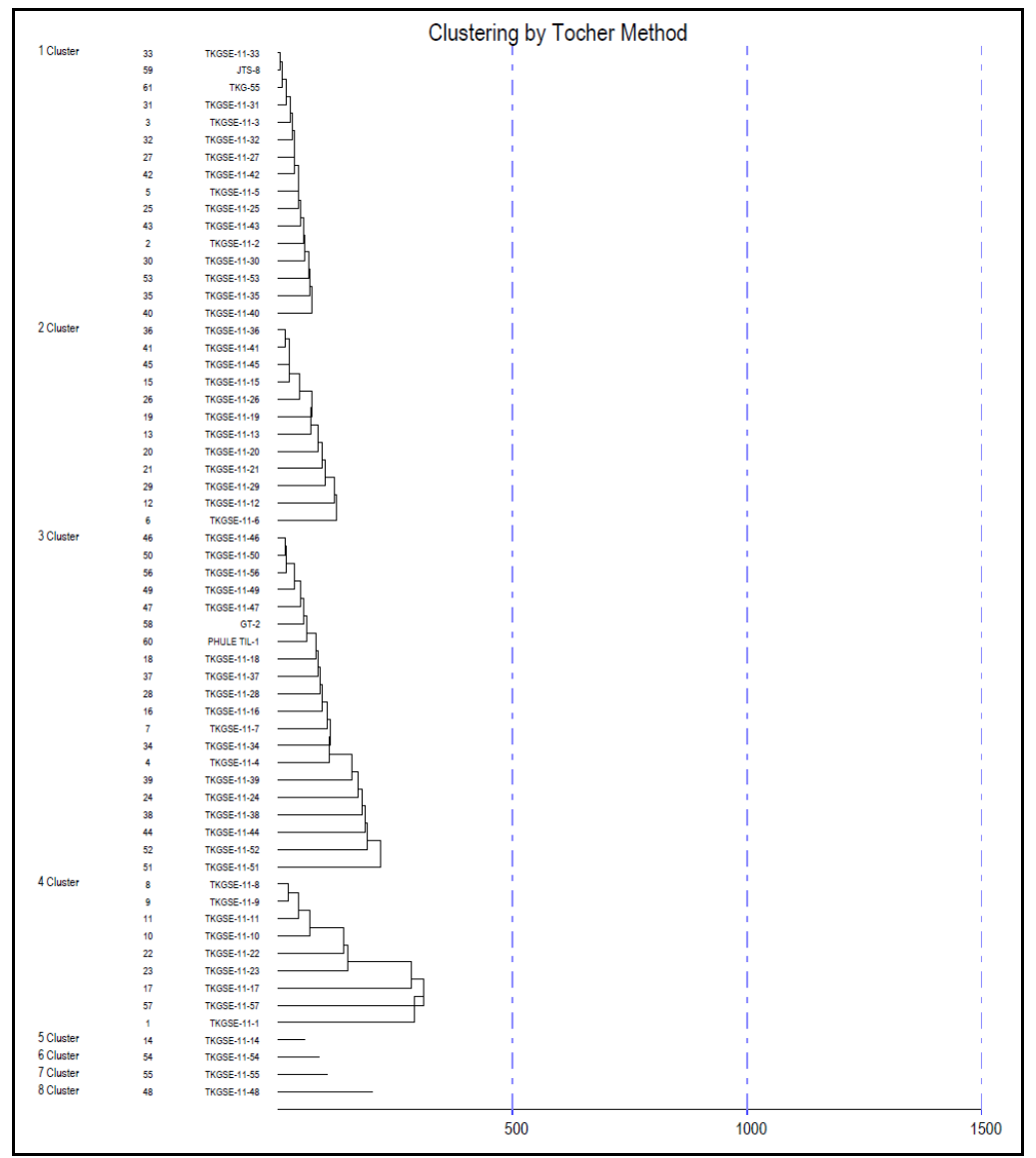

Fig 3: Dendrogram presenting the genetic relationship among different Sesamum indicum germplasm accessions used in the study during 2015. 


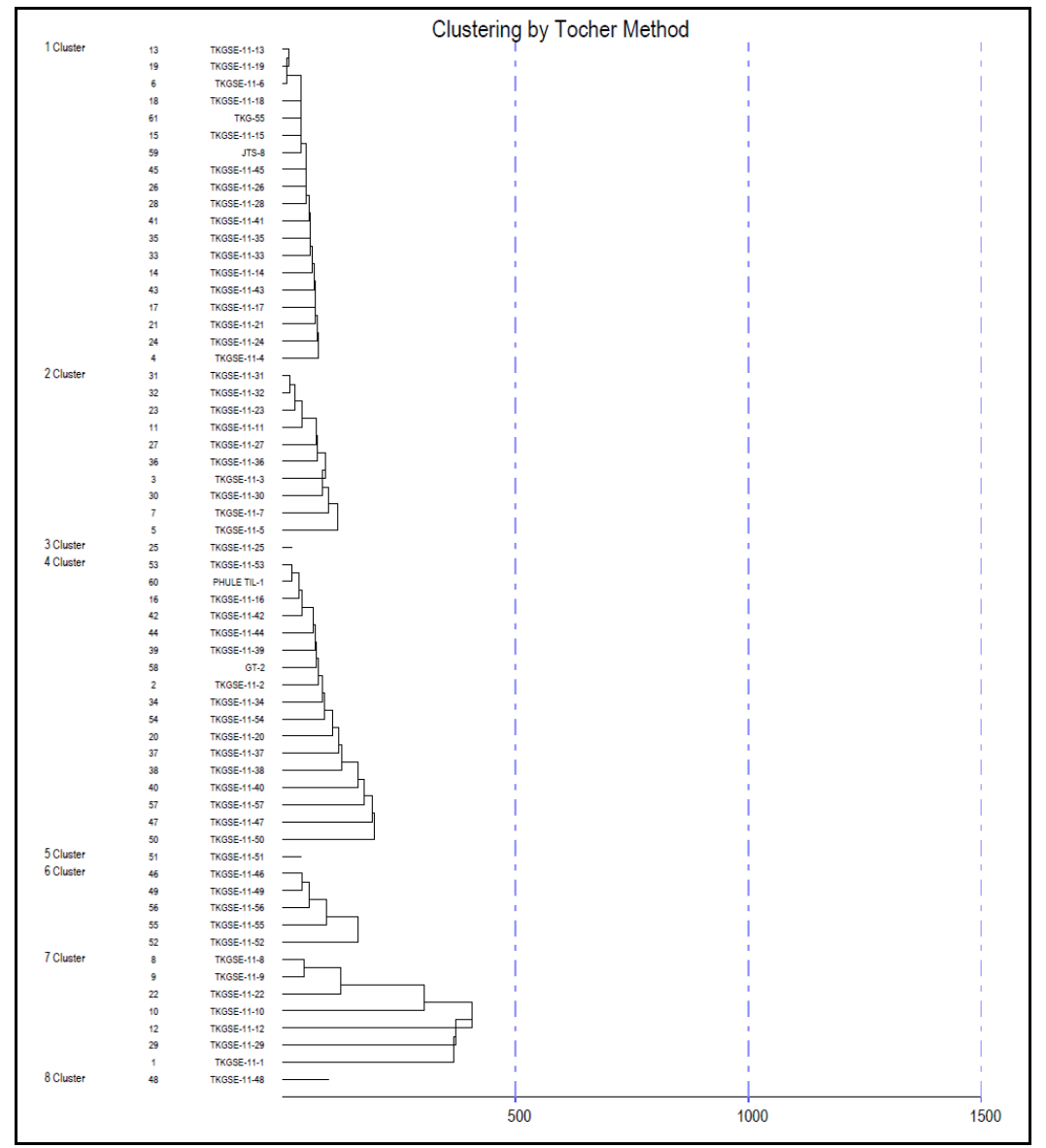

Fig 4: Dendrogram presenting the genetic relationship among different Sesamum indicum germplasm accessions used in the study during 2016.

Table 7: Cluster means for different characters in 61 genotypes, 2015

\begin{tabular}{|c|c|c|c|c|c|c|c|c|c|c|c|c|c|}
\hline Clusters & $\begin{array}{c}\text { Days to } \\
\mathbf{5 0 \%} \\
\text { Flowering }\end{array}$ & $\begin{array}{c}\text { Days to } \\
\text { Maturity }\end{array}$ & $\begin{array}{c}\text { Plant } \\
\text { Height } \\
\text { (cm) }\end{array}$ & $\begin{array}{c}\text { Branching } \\
\text { habit }\end{array}$ & $\begin{array}{l}\text { Capsule } \\
\text { Length }\end{array}$ & $\begin{array}{c}\text { Capsule/ } \\
\text { Plant }\end{array}$ & $\begin{array}{c}\text { Seeds/ } \\
\text { Capsule }\end{array}$ & $\mid \begin{array}{c}1000 \text { Seed } \\
\text { Weight } \\
(\mathrm{gm})\end{array}$ & $\begin{array}{c}\text { Seed } \\
\text { Yield/ } \\
\text { Plant } \\
(\text { gm) } \\
\end{array}$ & $\begin{array}{c}\text { Oil } \\
\text { Content } \\
(\%)\end{array}$ & $\begin{array}{c}\text { Oleic } \\
\text { Acid } \\
(\%)\end{array}$ & $\begin{array}{l}\text { Palmitic } \\
\text { Acid }(\%)\end{array}$ & $\begin{array}{l}\text { Linoleic } \\
\text { Acid (\%) }\end{array}$ \\
\hline $\mathrm{I}$ & 4 & 103.17 & 7409 & 1 & 2.34 & 42.78 & 69.87 & 3 & 4.94 & 42.43 & 26.76 & 2 & 40.69 \\
\hline II & & & & & & & & & 5.8 & & & & \\
\hline III & 73 & 103.56 & 70.72 & 1.43 & 2.34 & 46.67 & 57.21 & 2.86 & 5.68 & 42.34 & 27.98 & 8.09 & 45.30 \\
\hline IV & 39.82 & 100.57 & 92.86 & 2.38 & 2.21 & 43.78 & 77.54 & 2.44 & 5.00 & 44.10 & 26.05 & 7.81 & 42.58 \\
\hline $\mathrm{V}$ & 42.60 & 105.52 & 66.72 & 3.00 & 2.43 & 42.42 & 80.68 & 2.30 & 3.69 & 42.02 & 33.98 & 8.63 & 51.40 \\
\hline VI & & & & & & & & & 3.15 & & 23.91 & 4 & 42.51 \\
\hline VII & & & & & & & & & 4.95 & & & 10.27 & 38.28 \\
\hline VIII & 43.10 & 105.35 & 48.97 & 1.00 & 2.37 & 50.75 & 70.77 & 2.45 & 6.71 & 54.68 & 39.08 & 8.47 & 53.08 \\
\hline
\end{tabular}

Table 8: Cluster means for different characters in 61 genotypes: Sesame 2016

\begin{tabular}{|c|c|c|c|c|c|c|c|c|c|c|c|c|c|}
\hline Clusters & $\begin{array}{c}\text { Days to } \\
50 \% \\
\text { Flowering }\end{array}$ & $\begin{array}{l}\text { Days to } \\
\text { Maturity }\end{array}$ & $\begin{array}{c}\text { Plant } \\
\text { Height } \\
(\mathbf{c m})\end{array}$ & $\begin{array}{c}\text { Branching } \\
\text { habit }\end{array}$ & $\begin{array}{l}\text { Capsule } \\
\text { Length }\end{array}$ & $\begin{array}{c}\text { Capsules/ } \\
\text { Plant }\end{array}$ & $\begin{array}{c}\text { Seeds/ } \\
\text { Capsule }\end{array}$ & $\begin{array}{l}1000 \\
\text { SW } \\
(\mathrm{gm})\end{array}$ & $\begin{array}{l}\text { Seed } \\
\text { Yield/ } \\
\text { Plant } \\
(\text { gm) }\end{array}$ & $\begin{array}{c}\text { Oil } \\
\text { Content } \\
(\%)\end{array}$ & $\begin{array}{c}\text { Oleic } \\
\text { Acid } \\
(\%)\end{array}$ & $\begin{array}{l}\text { Palmitic } \\
\text { Acid (\%) }\end{array}$ & $\begin{array}{l}\text { Linoleic } \\
\text { Acid (\%) }\end{array}$ \\
\hline I & 42. & 70 & 7275 & 1.99 & 2.46 & 24.21 & 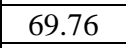 & 2.76 & 5.35 & 42.37 & 29.57 & 8.08 & 45.12 \\
\hline II & .93 & .08 & 4.17 & & & & & 3.05 & 5.32 & 43.24 & 26.46 & 8.58 & 39.01 \\
\hline III & 41.52 & 100.30 & 74.08 & 1.57 & 2.56 & 21.32 & 67.57 & 2.71 & 4.42 & 38.03 & 22.78 & 7.81 & 36.64 \\
\hline IV & 42.17 & 103.72 & 64.27 & 1.33 & 2.25 & 16.30 & 59.18 & 2.87 & 5.39 & 42.22 & 27.78 & 8.08 & 45.15 \\
\hline $\mathrm{V}$ & 40.18 & 108.38 & 53.92 & 0.07 & 2.29 & 2.02 & 63.90 & 2.58 & 6.78 & 40.28 & 30.88 & 8.34 & 49.71 \\
\hline VI & 4 & & 42.78 & & 2.03 & & & 2.71 & 4.71 & 43.82 & 29.72 & 8.61 & 45.38 \\
\hline VII & & & 89.44 & 2.59 & 2.45 & 37.13 & 73.66 & 2.43 & 5.45 & 44.91 & 27.98 & 7.49 & 43.23 \\
\hline VIII & 43.85 & 105.38 & 59.58 & 1.40 & 2.39 & 13.65 & 66.57 & 2.45 & 6.71 & 54.95 & 39.08 & 8.47 & 53.08 \\
\hline
\end{tabular}

\section{References}

1. Ahlawat S, Chhabra AK, Behl RK, Bisht SS. Genotypic divergence analysis for stay green characters in Wheat (Triticum aestivum L. em. Thell). The South Pacific Journal of Natural and Applied Sciences. 2008; 26(1):7381
2. Akbar F, Rabbani MA, Shinwari ZK, Khan SJ. Genetic divergence in sesame (Sesamum indicum L.) landraces based on qualitative and quantitative traits. Pakistan J. Bot. 2011; 43(6):2737-2744.

3. Ali MA, Abbas A, Awan SI, Jabran K, Gardezi SDA. Correlated response of various morpho-physiological 
characters with grain yield in sorghum landraces at different growth phases. J Anim Plant Sci. 2011; 21(4):671-679.

4. Allender CJ, King GJ. Origins of the amphiploid species Brassica napus L. Investigated by chloroplast and nuclear molecular markers. Plant Biol. 2010; 10:54-63.

5. Arriel NHC, Di Mauro AO, Arriel EF, Unêda-Trevisoli SH, Costa MM, Bárbaro IM et al. Genetic divergence in sesame based on morphological and agronomic traits. Crop Breeding and Applied Biotechnology, 2007, 253261.

6. Ashri A. Sesame breeding. Plant breeding reviews. 1998; 16:179-228.

7. Bedigian D, Smyth CA, Harlan JR. Patterns of morphological variation in Sesamum indicum. Economic Botany. 1986; 40(3):353-365.

8. Cheng $\mathrm{X}, \mathrm{Xu} \mathrm{J}$, Xia $\mathrm{S}, \mathrm{Gu} \mathrm{J}$, Yang $\mathrm{Y}, \mathrm{Fu} \mathrm{J}$ et al. Development and genetic mapping of microsatellite markers from genome survey sequences in Brassica napus. Theor. Appl. Genet. 2009; 118:1121-1131.

9. Dixit UN, Swain D. Genetic divergence and heterosis in sesame. Indian J. Genet. Plant Breed.2000; 60:213- 219.

10. Dossa K, DioufD, Wang L, Wei X, Zhang Y, Niang M, et al. The emerging oilseed crop Sesamum indicum enters the "Omics" era. Frontiers in plant science. 2017; 8:1154.

11. Furat S, UzunB. The use of agro-morphological characters for the assessment of genetic diversity in sesame (Sesamum indicum L). Plant Omics. 2010; 3(3):85.

12. GolabadiM, Arzani A, Maibody SM. Assessment of drought tolerance in segregating populations in durum wheat. African Journal of Agricultural Research. 2006; 1(5):162-171.

13. Gomez KA, GomezAA. Statistical procedures for agricultural research. John Wiley and Sons, 1984.

14. Gómez-Campo C. Taxonomy. In: C. Gómez-Campo (ed.), Biology of Brassica coenospecies. Elsevier, Amsterdam; 1999, 3-32.

15. HikaG, Geleta N, Jaleta Z. Correlation and Divergence Analysis for Phenotypic Traits in Sesame (Sesamum indicum L.) Genotypes. Science, Technology and Arts Research Journal. 2015; 3(4):01-09.

16. Menzir A. Phenotypic variability divergence analysis and heritability of characters in sesame (Sesamum indicum L.) genotypes. Nature and Science. 2012; 10(10):117126.

17. Mohamed AE, BourkeP, Germaine K, MaloneR. Assessment of morphological variation in irish $B$. oleracea species. J Agric. 2012; 4:20-34.

18. Mohammadi SA, Prasanna BM. Analysis of genetic diversity in crop plants-salient statistical tools and considerations. Crop science. 2003; 43(4):1235-1248.

19. Namiki M. Nutraceutical functions of sesame: a review. Critical reviews in food science and nutrition.2007; 47(7):651-673.

20. Pathak N, RaiAK, Kumari R, Bhat KV. Value addition in sesame: A perspective on bioactive components for enhancing utility and profitability. Pharmacognosy reviews. 2014; 8(16):147.

21. Pandey SK, Das A, Rai P, Dasgupta T. Morphological and genetic diversity assessment of sesame (Sesamum indicum L.) accessions differing in origin. Physiology and molecular biology of plants. 2015; 21(4):519-529.
22. Pathirana R. Natural Cross Pollination in Sesame (Sesamum indicum L.). Plant breeding. 1994; 112(2):167170.

23. Rai SK, Charak D, Bharat R. Scenario of oilseed crops across the globe. Plant Archives. 2016; 16(1):125-132.

24. Ram R, Catlin D, Romero J, Cowley C. Sesame: new approaches for crop improvement. In: Janick J. and Simon J.E. (eds) Advances in new crops. Portland, Timber Press. 1990, 225-228.

25. Siddiqui MH, AliS, Bakht J, Khan A, Sher AK, Nadir K. Evaluation of Sunflower and their crossing combinations for morphological characters, yield and oil contents. Pak. J. Bot.2012; 44:687-690.

26. Smykal P, Horacek J, Dostalova R, Hybl M. Variety discrimination in pea (Pisum sativum L.) by molecular, biochemical and morphological markers. J. Appl. Genet., 2008; 49:155-166.

27. Sneath PH, Sokal RR. Numerical taxonomy. The principles and practice of numerical classification, 1973.

28. SolankiZS, Gupta D. Variability and character association among quantitative characters of sesame. Journal of Oilseeds Research. 2003; 20:276-277.

29. Trick M, Long Y, Meng J, Bancroft I. Single nucleotide polymorphism (SNP) discovery in the polyploid Brassica napus using Solexa transcriptome sequencing. Plant Biotechnol. J. 2009; 7:334-346.

30. Tripathi A, Bisen R, Ahirwal RP, Paroha S, Sahu R, Ranganatha ARG. Study on genetic divergence in sesame (Sesamum indicum L.) germplasm based on morphological and quality traits. The Bioscan. 2013; 8(4):1387-1391.

31. Wei X, Liu K, Zhang Y, Feng Q, Wang L, Zhao Y et al. Genetic discovery for oil production and quality in sesame. Nature communications. 2015; 6:860.

32. Weiss EA. Oilseed crops, 2nd edn. Oxford, Blackwell Science, 2000, 131-164.

33. Were BA, Onkware AO, Gudu S, Welander M, Carlsson AS. Seed oil content and fatty acid composition in East African sesame (Sesamum indicum L.) accessions evaluated over 3 years. Field crops research. 2006; 97(2):254-260. 